\title{
Estudio de factibilidad para la implementación de una planta generadora de energía eléctrica en la UNAH, utilizando celdas de combustible a base de gas metano
}

\author{
Dennis A. Rivera * \\ Juan F. Méndez * \\ Leonardo Herrera *
}

\section{RESUMEN}

El presente trabajo, surge como una necesidad dada la crisis energética que atraviesa el sector eléctrico hondureño debido al elevado costo del petróleo, la falta de generación de energía eléctrica en base a recursos renovables y al considerable derroche de energía eléctrica, lo que causa la excesiva demanda energética de la Universidad Nacional Autónoma de Honduras (UNAH) hacia la Empresa Nacional de Energía Eléctrica (ENEE). El estudio se basó en determinar la factibilidad técnica de implementar una central generadora DFC300MA, fabricada por la compañía Fuel Cell Energy, la cual cuenta con una capacidad de generación de $300 \mathrm{~kW}$. El combustible requerido para alimentar dicha planta se conoce como biogás; el cual en su mayoría está compuesto de gas metano ( $\mathrm{CH} 4)$. Este se planeó obtener a partir de la basura y las aguas residuales desechadas en la Ciudad Universitaria; para ello se hace necesaria la implementación de biodigestores.

Finalmente se determinó, que un proyecto de este tipo no resulta factible de implementar en la Ciudad Universitaria; debido a que la cantidad de basura disponible (4.5 Toneladas diarias) y las aguas residuales $\left(50 \mathrm{~m}^{3}\right.$ por hora), propias de la universidad, sólo podrían generar $31.25 \mathrm{Kw}$ de los $300 \mathrm{Kw}$ que puede generar la planta; lo cual representa una mala inversión y al mismo tiempo no se cumple con la demanda energética establecida. De igual forma, se analizó la implementación de un proyecto de este tipo aplicado al basurero municipal de Tegucigalpa; resultando que es posible generar 5.5Mw de potencia; lo que resultaría una valiosa contribución

\footnotetext{
*DennisA. Rivera, dealriv@yahoo.com

Profesor de laFacultadde Ingeniería, Escuelade Ingeniería Civil. Universidad Nacional Autónoma de Honduras. *Juan F. Méndez, estudiante egresado, en proceso de obtención del titulo de ingeniero electricista industrial de la Universidad Nacional Autónoma de Honduras, UNAH.

*Leonardo Herrera, estudiante egresado, en proceso de obtención del titulo de ingeniero electricista industrial de la Universidad Nacional Autónoma de Honduras, UNAH.
} 
Ala reducción de la creciente demanda energética que enfrenta la ENEE.

Palabras Clave: Energía eléctrica, Recursos renovables, Tratamiento de desechos y Biogás

\section{ABSTRACT}

The present work arises as a need given the energy crisis in the electrical sector of Honduras due to high oil prices, lack of generation of electrical energy from renewable resources and the considerable energy expenditure because of the energy demand of the National Autonomous University of Honduras (UNAH) from the National Enterprise of Electrical Energy (ENEE). The study was based on determining the technical feasibility of implementing a DFC300MA generator, made by the Fuel Cell Energy company, which has a capacity to generate $300 \mathrm{KW}$. The fuel required for this generator is known as biogas; which is mainly composed of methane $(\mathrm{CH} 4)$. The methane will be obtained from the garbage and hard water (Sewage) from the university campus; in order to do this, biodigestors must be implemented.

Finally, it was determined that a project of this kind is not feasible at the University Campus because the amount of garbage available (4.5 tons daily) and the hard waters $\left(50 \mathrm{~m}^{3}\right.$ per hour) could only generate $31.25 \mathrm{Kw}$ of the $300 \mathrm{Kw}$ the generator can produce, which is not only a bad investment in terms of equipment but also does not fulfill de energy demand of the UNAH. The implementation of a project of this kind applied to the municipal Dump of Tegucigalpa was also analyzed. It turned out that it is feasible to generate $5.5 \mathrm{Mw}$ of power, which would result in a valuable contribution to the energy supply problems the ENEE is facing.

Keywords: electricity, renewable resources, biogas, waste managment 


\section{INTRODUCCIÓN}

El presente trabajo es un estudio para determinar la factibilidad técnica de implementar un proyecto de generación de energía eléctrica en base a celdas de combustible alimentado con biogás (metano). Se presenta la descripción de una celda de combustible, los tipos y aplicaciones de cada una, continuando con desglose de términos y aspectos de importancia como son biogás, biodigestores, plantas para tratamientos de aguas residuales y culminando el trabajo con un análisis de factibilidad técnica, con el cual se determinará si resulta conveniente 0 no, la implementación de este tipo de proyectos, lo que resulta en beneficio para toda la comunidad universitaria de la Universidad Nacional Autónoma de Honduras (UNAH).

\section{1. ¿Qué es una celda de combustible?}

Una celda de combustible consiste en dos electrodos separados por un electrolito. Oxígeno pasa sobre un electrodo e hidrógeno sobre el otro. Cuando el hidrógeno es ionizado pierde un electrón y al ocurrir esto ambos (hidrógeno y electrón) toman diferentes caminos hacia el segundo electrodo. El hidrógeno migra hacia el otro electrodo a través del electrolito mientras que el electrón lo hace a través de un material conductor Fig.1. Este proceso producirá agua, corriente eléctrica y calor útil.

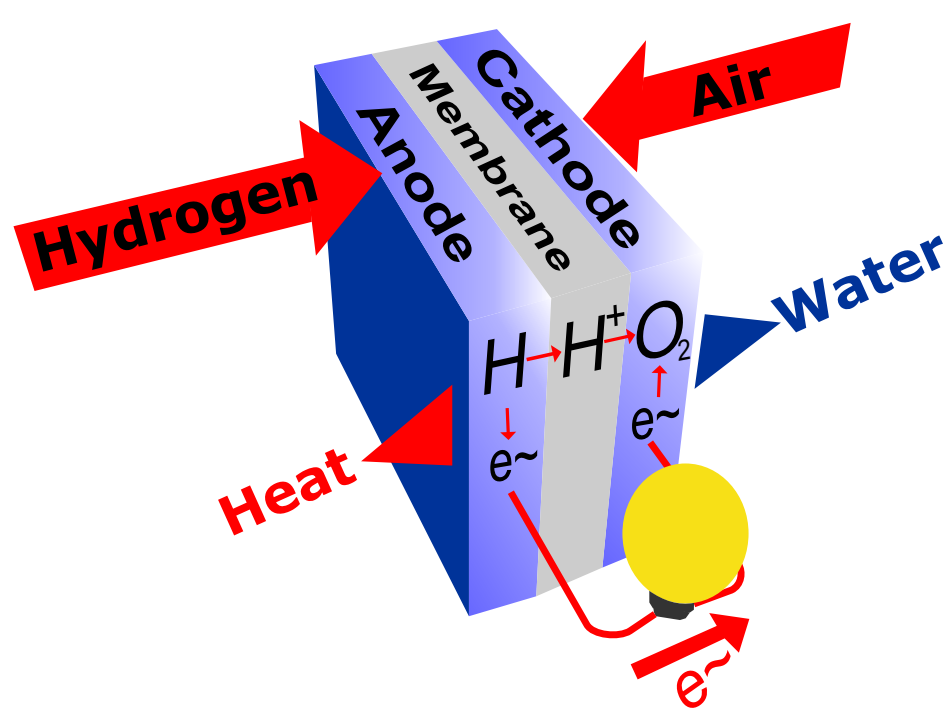

Fig.1. Funcionamiento de una celda de combustible. 


\section{Tipos de celdas de combustibles}

Las celdas de combustible son en realidad una familia de tecnologías que usan diferentes electrólitos y que operan a diferentes temperaturas; su clasificación es la siguiente:

- Ácido Fosfórico (PAFCs)

- Polímero Sólido ó Membrana de Intercambio Protónico (PEM)

- Carbonato Fundido (MCFCs)

- Óxido Sólido (SOFCs)

- Alcalinas

- Metanol Directo (DFC)

\section{3. ¿Que tipo de combustibles pueden usarse en celdas de combustible?}

Las celdas de combustible permiten promover una diversidad de energía y una transición hacia fuentes de energía renovables. Así, una variedad de distintos combustibles pueden ser usados en estas, combustibles tales como hidrógeno (Fig.2), Biogás (metano), etano, gas natural así como gas licuado (LPG). La energía también podría ser provista a partir de biomasa, sistema eólico ó bien solar.

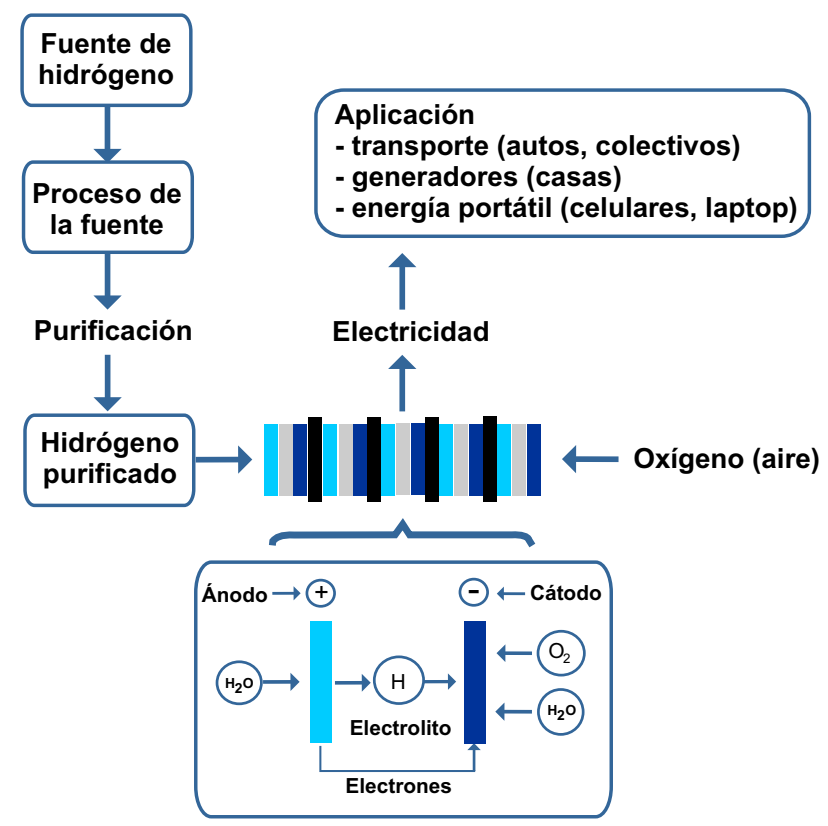

Fig. 2 Celda de combustible alimentada con hidrogeno y aplicaciones 


\section{Distintas formas de obtención de hidrógeno}

El hidrógeno es un combustible que no se encuentra en su estado natural. No obstante puede obtenerse a partir de gas natural o de biogás, Por lo tanto, es un combustible de los llamados secundarios. El hidrógeno utilizado en las celdas de combustibles puede obtenerse de varias formas, empleando diversos equipamientos y combustibles. (Fig.3).

- Apartir del agua y una fuente de calor electricidad

- Apartir del agua y la energía solar

- A partir de metano

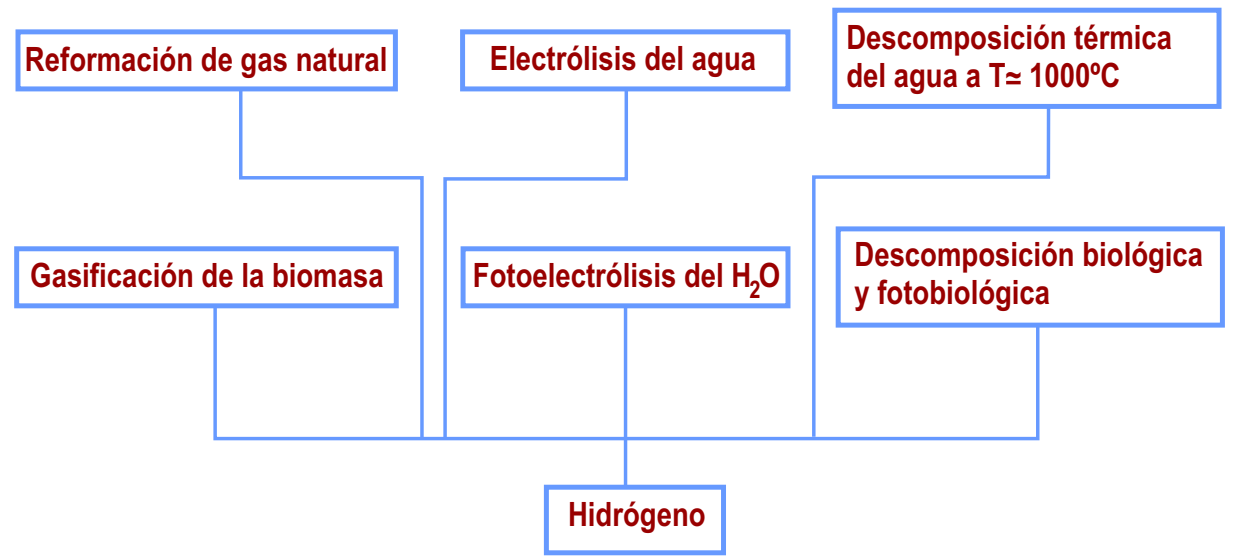

Fig.3 Obtención de hidrógeno

\section{5. ¿Qué es el biogás?}

El biogás es un gas producido por bacterias durante el proceso de biodegradación de material orgánico en condiciones anaeróbicas (sin aire). La generación natural de biogás es una parte importante del ciclo biogeoquímico del carbono. El metano, Tabla 1, producido por bacterias es el último eslabón en una cadena de microorganismos que degradan material orgánico y devuelven los productos de la descomposición al medio ambiente. 
Tabla 1. Composición de biogás

\begin{tabular}{|l|l|}
\hline \multicolumn{1}{|c|}{ Componentes } & \multicolumn{1}{c|}{ Biogás } \\
\hline Metano (CH4) & $50-70$ \\
\hline Etano (C2H6) & 0 \\
\hline Propano (C3H8) & 0 \\
\hline Butano (C(H10) & 0 \\
\hline Dióxido de carbono (CO2) & $25-45$ \\
\hline Hidrógeno (H2) & $1-10$ \\
\hline Nitrógeno (N2) & $0,3-3$ \\
\hline Oxígeno (O2) & $0-2$ \\
\hline Poder calorífico (PCS base seca) & $20-24 \mathrm{MJ} / \mathrm{Nm3}$ \\
\hline Componentes traza & $0-200 \mathrm{mg} / \mathrm{Nm} 3$ \\
Compuesto de azufre & $0-50 \mathrm{mgC} 1 / \mathrm{Nm} 3$ \\
Componentes clorados &
\end{tabular}

\section{Factores asociados a la generación de biogás}

Los principales factores que influyen sobre la producción de biogás en el tiempo son: Cantidad, calidad y edad de los desechos dispuestos. Después de un incremento rápido, la producción de $1 \mathrm{~m}^{3}$ de biogás disminuye regularmente. Según los tipos de desechos, se consideran tres tipos de velocidad de degradación del carbono:

- Degradación rápida; desechos vegetales y alimenticios, 1.5 a 2 años;

- Degradación media; desechos vegetales y alimenticios, 5 a 10 años;

- Degradación lenta; cartón, madera, cuero, 10 a 20 años o más

Según la composición media de los desechos, se puede estimar la degradabilidad media del carbono, según las siguientes consideraciones:

- Agua

- Temperatura

- Productos químicos

\section{Substratos para la producción de biogás}

El substrato es el material de partida en la producción de biogás. En principio, todos los materiales orgánicos pueden fermentar o ser digeridos. Sin embargo, 
sólo algunos pueden ser utilizados como sustratos en plantas de producción sencillas. Excremento y orina de vacas, cerdos y posiblemente aves de corral son algunos ejemplos. Aveces, también pueden usarse los desperdicios de las plantas de producción de alimentos. La máxima producción de gas que se puede conseguir a partir de una cantidad dada de materia prima depende del sustrato que se utilice, ver Tabla 2.

Tabla 2 Volumen de biogás generado

\begin{tabular}{|l|c|}
\hline \multicolumn{1}{|c|}{ Sustrato } & $\begin{array}{c}\text { Cantidad de biogás a } 30^{\circ} \mathrm{C} \\
\text { en } / / \mathrm{kg} \text { de residuo seco }\end{array}$ \\
\hline Estiércol con paja & 286 \\
\hline Excrementos de vaca & 237 \\
\hline Excrementos de cerdo & 257 \\
\hline Agua residual urbana & 100 \\
\hline
\end{tabular}

\section{BIODIGESTORES}

Un biodigestor es una instalación en la que mediante la descomposición de los desechos sólidos (basura), bajo condiciones anaeróbicas (sin aire), se genera biogás; que como se mencionó anteriormente, se usaría como combustible.

\section{Tipos de biodigestores}

Según su forma de operación se clasifican en (ver Fig. 4):

- Pozos sépticos

- Biodigestor de estructura flexible

- Biodigestor del domo flotante

- Biodigestor de domo fijo

- Relleno sanitario 


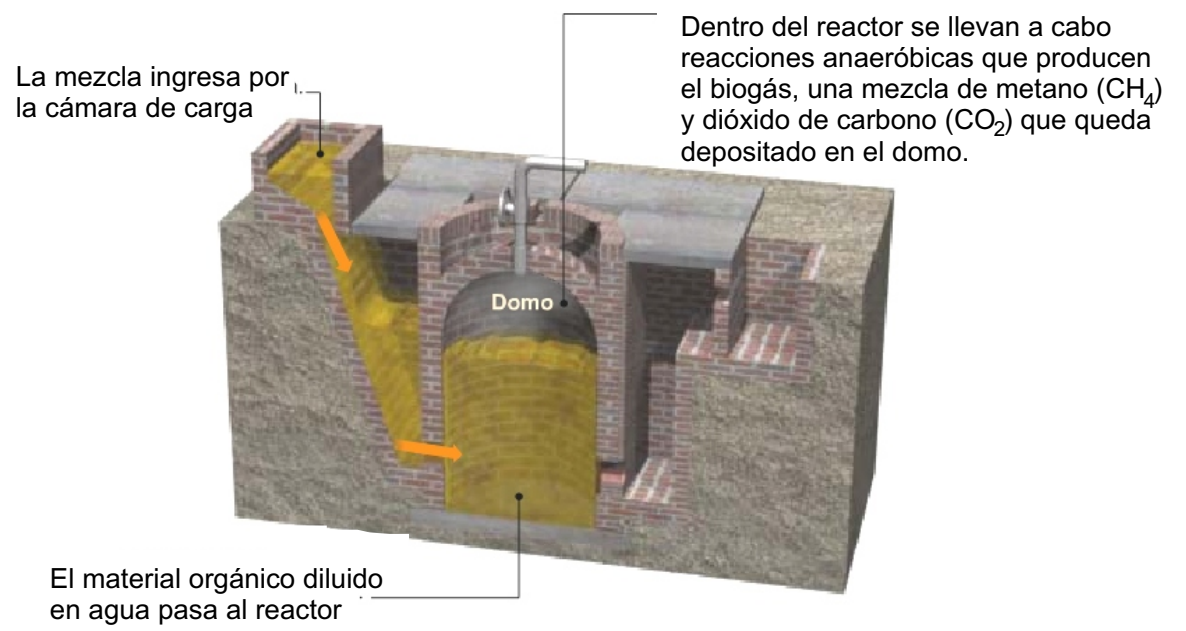

Fig.4 Biodigestor de domo fijo

\section{Relleno sanitario}

Un relleno sanitario es un gigantesco biodigestor anaerobio que tiene el potencial de producir energía renovable a partir del metano contenido en el biogás. La Fig. 5 indica la ubicación general típica de los componentes y cobertura de un relleno sanitario. Aquí se esquematizan el transporte y disposición de los RSU, las etapas progresivas de relleno y ubicación de las celdas, el drenaje de lixiviados, el equipo de compactación, la cuneta perimetral de escorrentías, la valla perimetral, las teas, los pozos de perforación y la empradización de las zonas clausuradas.

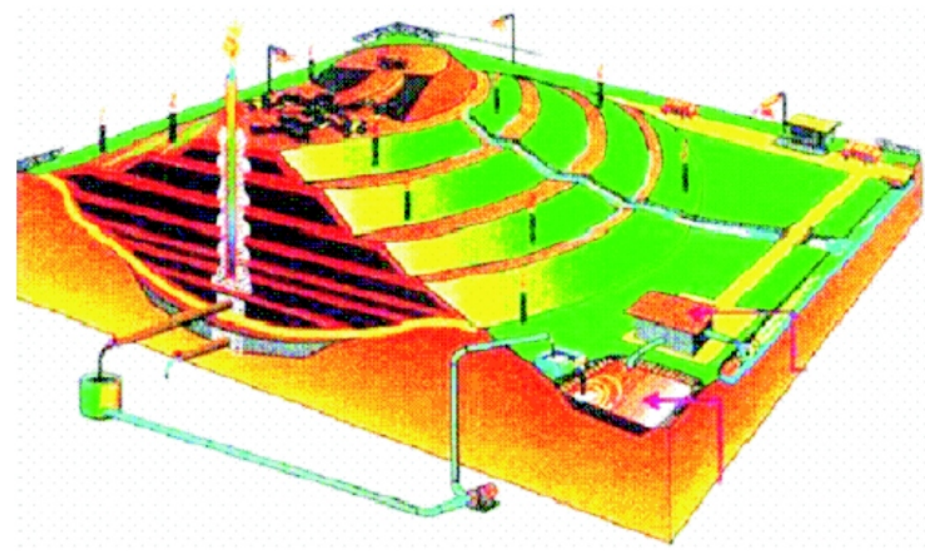

Fig. 5 Relleno sanitario 


\section{Planta de tratamiento de aguas residuales}

El digestor UASB- Los reactores tipo UASB, ver Fig.6, son los sistemas de tratamiento anaerobios más difundidos en América Latina y han sido utilizados a partir de 1980 para el tratamiento directo de las aguas residuales domésticas e industriales. De algún modo los UASB, ver Fig.6 Reemplazan en las plantas de tratamiento a los sedimentadores primarios, los sedimentadores secundarios, las lagunas de oxidación y gran parte de los sistemas de lodos activados, pues logran eficiencias de remoción comprendidos entre el 60 y el $80 \%$ de la DQO y DBO (demanda quimica y bioquímica de oxígeno), en función de la concentración inicial del agua residual. Adicionalmente las plantas UASB generan 3 subproductos valiosos y comercializables: biogás, lodo estabilizado seco y agua tratada rica en nutrientes.

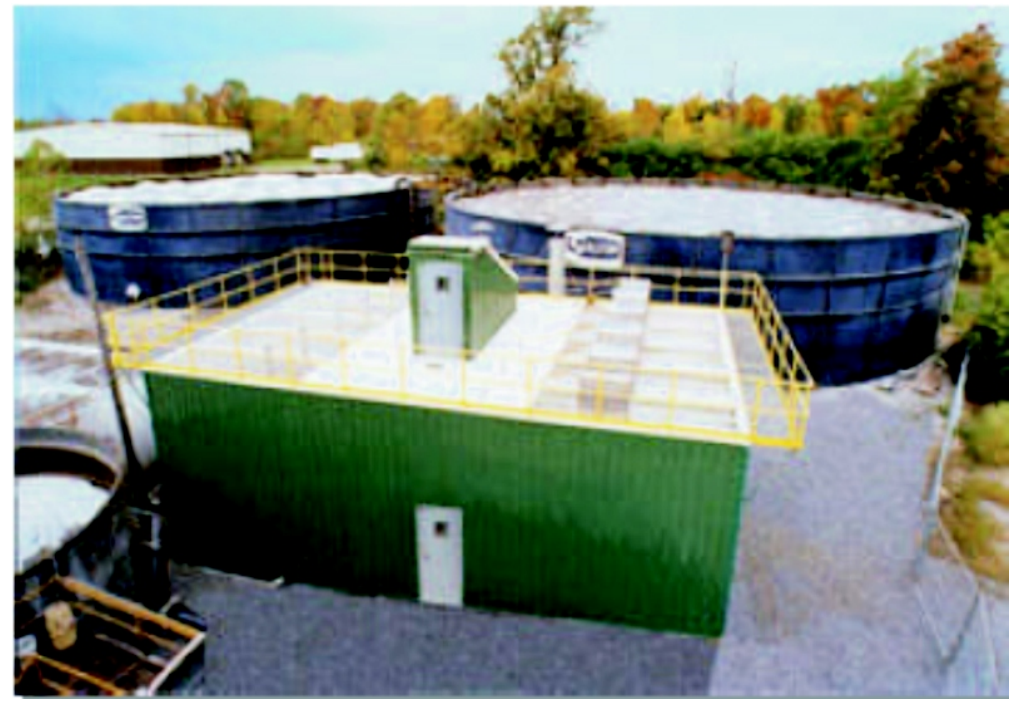

Fig.6 Planta compacta UASB

\section{CONSUMO DE ENERGÍAEN LAUNAH}

Este análisis comprende el estudio de la demanda de la UNAH durante el año 2006 (Tabla 3). Puede observarse que el consumo mensual varía, como es de esperarse, debido al calendario académico establecido para un año fijo, ya que en periodos en los cuales no hay clases el consumo se reduce (ver Enero, Junio y Diciembre) y aumenta en los meses calurosos o de mucha actividad académica (ver Mayo y Noviembre). 
Tabla 3 Detalle de la facturación mensual de la UNAH (facilitado por la ENEE)

\begin{tabular}{|l|r|}
\hline Mes & Consumo kwh \\
\hline Enero & 170,100 \\
\hline Febrero & 343,000 \\
\hline Marzo & 395,500 \\
\hline Abril & 354,900 \\
\hline Mayo & 418,600 \\
\hline Junio & 291,200 \\
\hline Julio & 347,200 \\
\hline Agosto & 330,400 \\
\hline Septiembre & 329,700 \\
\hline Octubre & 379,400 \\
\hline Noviembre & 406,000 \\
\hline Diciembre & 296,800 \\
\hline TOTAL & $\mathbf{4 , 0 6 2 , 8 0 0}$ \\
\hline
\end{tabular}

\section{LA“DFC300MA" DEFUEL CELL ENERGY}

Debido a la demanda energética de La UNAH y a la disposición de las compañías que fabrican este tipo de plantas se decidió analizar el proyecto para una planta DFC 300MA, ver Fig.7, fabricada por Fuel Cell Energy; la cual genera 300kW y estará funcionando con un promedio de 11.25 horas diarias de lunes a viernes, específicamente a las horas de mayor consumo comprendidas desde las 10:45 h hasta las 22:00 h.

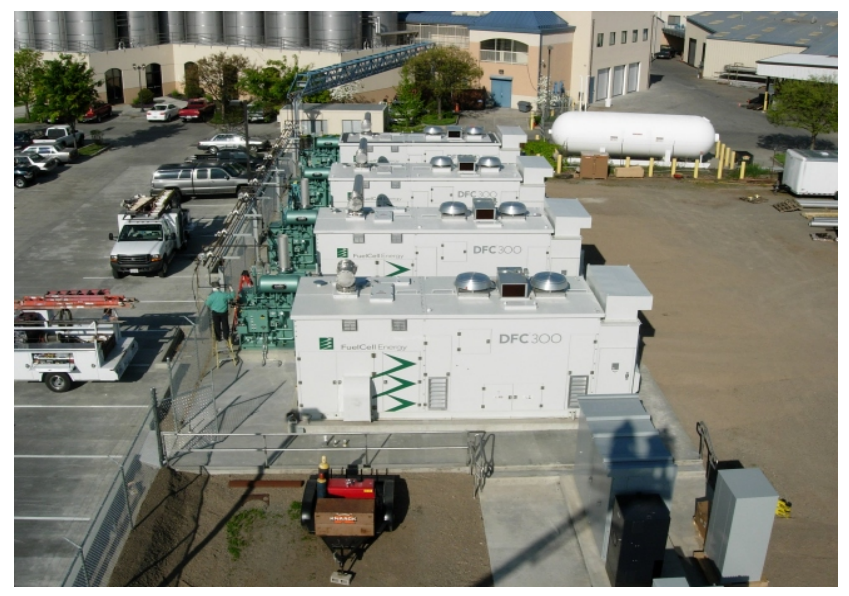

Fig. 7 Central de generación eléctrica DFC300MA 


\section{ESTUDIO DE LAS ALTERNATIVAS PARALA GENERACIÓN DE BIOGÁS}

Debido a los requerimientos de la planta a utilizar $\left(78 \mathrm{~m}^{3} / \mathrm{h}\right.$ de biogás) y a las posibilidades de obtener biogás a partir de los desechos sólidos y de las aguas residuales propias de la ciudad universitaria, se hace necesario estimar la cantidad de biogás que podemos generar con dichos recursos; para ello utilizaremos un programa para computadora llamado: "El Modelo Centroamericano de Biogás".

\section{El modelo centroamericano de biogás}

El Modelo Centroamericano de Biogás provee una herramienta automática para la estimación de la generación y recuperación de biogás en rellenos sanitarios en Belice, Costa Rica, El Salvador, Guatemala, Honduras, Nicaragua y Panamá. El principal propósito del Modelo Centroamericano de Biogás es proveer a propietarios u operadores de rellenos sanitarios con una herramienta para evaluar la factibilidad y beneficios de recuperar y usar el biogás generado.

El biogás es generado por la descomposición de residuos en un relleno sanitario, y puede ser recuperado bajo la operación de un sistema de recuperación de biogás construido en el mismo relleno sanitario. La siguiente información es necesaria para estimar la generación y recuperación del biogás en un relleno sanitario:

- Capacidad de diseño del relleno sanitario

- La cantidad de residuos depositados en el relleno sanitario, o el índice de aceptación anual estimado

- El índice de generación de metano $(\mathrm{k})$

- La generación potencial de metano (LO)

- La eficiencia del sistema de recolección de biogás; $y$

- Los años de operación a la fecha y los años que se planea operar.

El método utiliza una ecuación de degradación de primer orden (Fig 8) que asume que la generación de biogás llega a su máximo después de un periodo de tiempo antes de la generación de metano. El modelo asume que el período es de seis meses desde la colocación de los residuos y el comienzo de la generación de biogás. El modelo asume que por cada unidad de residuos, después de seis meses la generación disminuye exponencialmente mientras la fracción orgánica de los residuos es consumida. 


$$
\begin{aligned}
& \text { 1. } 1 \\
& \underset{\mathrm{i}=1 \mathrm{j}=01}{\mathrm{Q}_{\mathrm{N}}}=\sum \sum 2 \mathrm{~kL}_{0}\left(\mathrm{M}_{\mathrm{i}} / 10\right)\left(\mathrm{e}^{-\mathrm{kt} \mathrm{ij}}\right)
\end{aligned}
$$

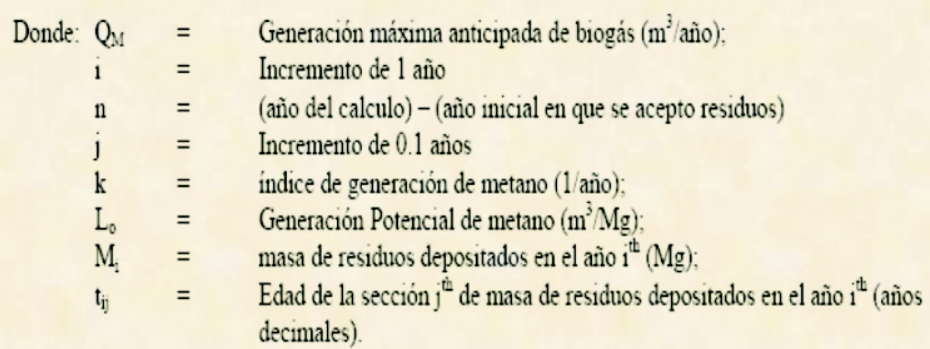

Fig. 8 Ecuación utilizada por el modelo

\section{Predicción de generación de biogás en la UNAH, utilizando el modelo centroamericano}

Ingresando los datos de la cantidad de basura desechada anualmente en la Ciudad Universitaria $(1,066$ Ton/año) con un incremento del $0.1 \%$ anual y la precipitación anual en Tegucigalpa, $940 \mathrm{~mm}$ por año; en El Modelo Centroamericano de Biogás; obtenemos los siguientes resultados, ver Tabla 4. El estudio asume que la planta empezaría a funcionar en Enero del 2008 y tendría una vida útil de 30 años.

Tabla 4. Predicción de generación de biogás en la UNAH

\begin{tabular}{|c|c|c|c|c|c|c|c|}
\hline \multicolumn{8}{|c|}{$\begin{array}{c}\text { GENERACIÓN DE BIOGÁS } \\
\text { UNAH, TEGUCIGALPA, M.D.C., HONDURAS }\end{array}$} \\
\hline \multicolumn{3}{|c|}{ Generación de Biogás } & \multicolumn{3}{|c|}{$\begin{array}{l}\text { Capacidad máxima } \\
\text { Planta de energía* }\end{array}$} & \multicolumn{2}{|c|}{$\begin{array}{l}\text { Estimados de reducción } \\
\text { en emisiones de Metano** }\end{array}$} \\
\hline Año & $\left(\mathrm{M}^{3} / \mathrm{hr}\right)$ & (Cfm) & (MmBtu/hr) & $(M W)$ & & H/año) & (Tonnes $\mathrm{CO}_{2}$ eq/año) \\
\hline 2038 & 18 & 11 & 0.3 & 0.0 & & & 725 \\
\hline 2039 & 19 & 11 & 0.3 & 0.0 & & & 734 \\
\hline 2040 & 19 & 11 & 0.3 & 0.0 & & & 743 \\
\hline 2041 & 19 & 11 & 0.3 & 0.0 & & & 751 \\
\hline 2042 & 19 & 11 & 0.3 & 0.0 & & & 760 \\
\hline 2043 & 19 & 11 & 0.3 & 0.0 & & & 768 \\
\hline 2044 & 20 & 12 & 0.4 & 0.0 & & & 777 \\
\hline 2045 & 20 & 12 & 0.4 & 0.0 & & & 785 \\
\hline 2046 & 20 & 12 & 0.4 & 0.0 & & & 793 \\
\hline 2047 & 20 & 12 & 0.4 & 0.0 & & & 801 \\
\hline 2048 & 20 & 12 & 0.4 & 0.0 & & & 810 \\
\hline
\end{tabular}
(en los últimos 10 años de la planta) 


\section{ANÁLISIS DE LOS RESULTADOS}

De los resultados obtenidos por el modelo, se observa que la generación máxima de biogás es de $20 \mathrm{~m}^{3} / \mathrm{h}$ (35 años después de iniciado el proyecto); Además se conoce que:

$$
\begin{aligned}
& 1 \mathrm{~m}^{3}(\text { biogás }) / \text { h equivale a: } 1.25 \mathrm{kwh} \\
& \left.1 \mathrm{~m}^{3}\left(\mathrm{AR}^{*}\right) / \mathrm{h} \text { equivale a: } 0.1 \mathrm{~m}^{3} \text { (biogás }\right) / \mathrm{h}
\end{aligned}
$$

Esto es:

$$
50 \mathrm{~m}^{3}\left(\mathrm{AR}^{*}\right) / \mathrm{h}=5 \mathrm{~m}^{3}(\text { biogás }) / \mathrm{h}
$$

Así:

$20 \mathrm{~m}^{3}$ (biogás)/h equivalen a: $25 \mathrm{~kW}$

$5 \mathrm{~m}^{3}$ (biogás)/h equivalen a: $6.25 \mathrm{~kW}$

${ }^{*} \mathrm{AR}=$ Aguas Residuales

De lo anterior podemos concluir que la potencia máxima que se puede generar a partir de los desechos propios de La UNAH es de $31.25 \mathrm{~kW}$; esto representa aproximadamente el $11 \%$ de la potencia que puede generar la planta (DFC300MA).

\section{PREDICCIÓN DE GENERACIÓN DE BIOGÁS EN EL BASURERO MUNICIPAL DE TEGUCIGALPA}

De igual forma que para el caso de la UNAH, podemos obtener una predicción, un estudio de factibilidad técnica, en cuanto a un proyecto de generación de energía eléctrica utilizando los RSM. En la Tabla 5 Ilustra la máxima generación de potencia (5.5Mw), así como un estimado en la reducción de metano y dióxido de carbono (como gases que contribuyen al efecto invernadero). De igual forma en la Fig. 9 estima la posible generación de biogás para el proyecto, teniendo en cuenta que la cantidad de desechos sólidos en la Capital es de 310,250 Ton al año, ver Fig.10. 


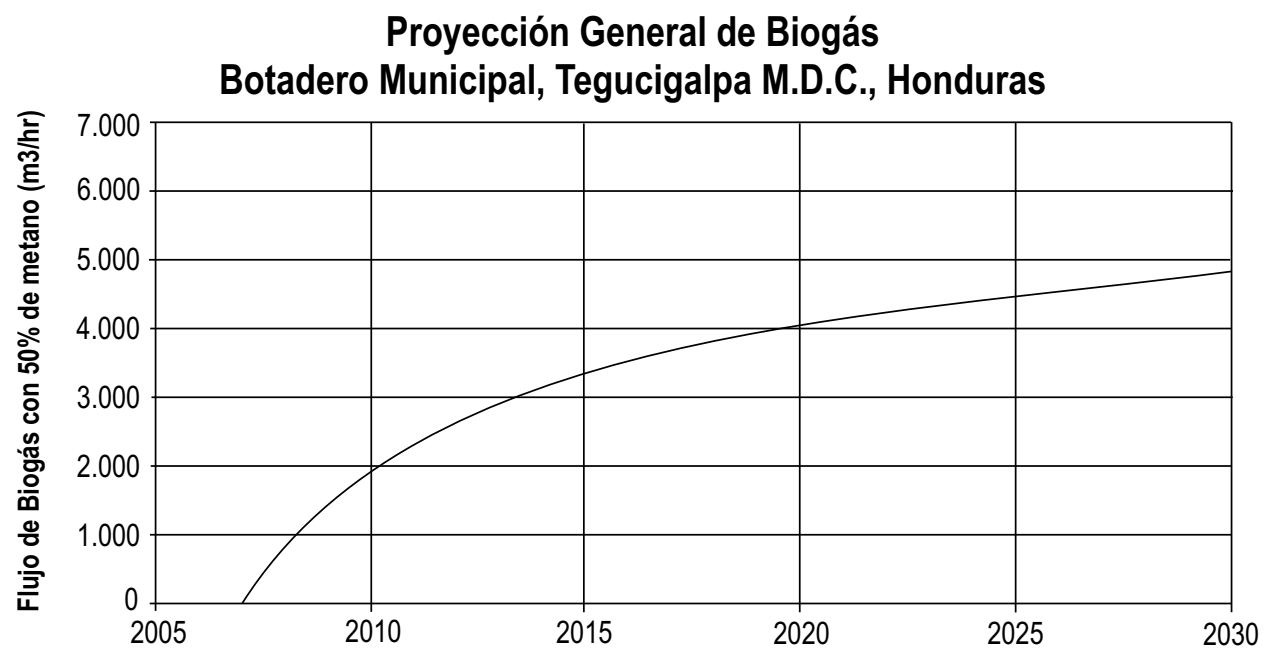

Fig. 9 Predicción de generación de biogás para los últimos 10 años del proyecto.

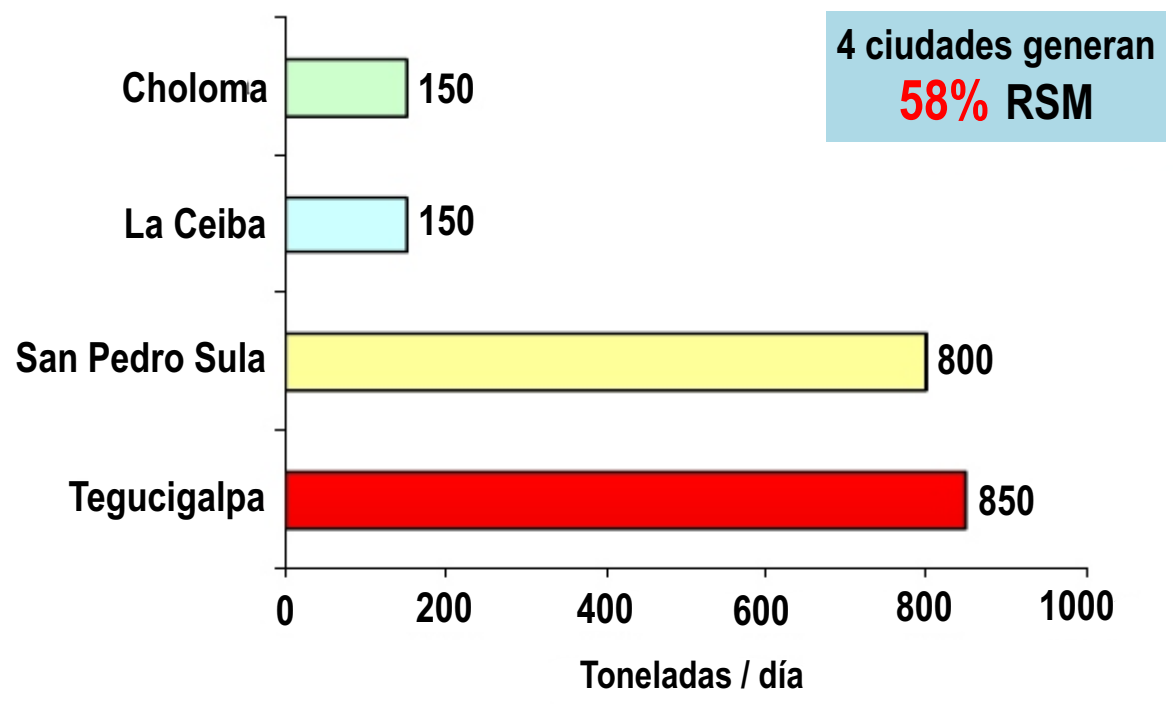

\section{Total Nacional: 3,337 ton/día ( $0.45 \mathrm{~kg} / \mathrm{per} / \mathrm{día})$}

Fig.10 Generación de RSM en las principales ciudades 
Tabla 5. Aplicación del modelo centroamericano de biogás al basurero municipal (en los últimos 10 años del proyecto)

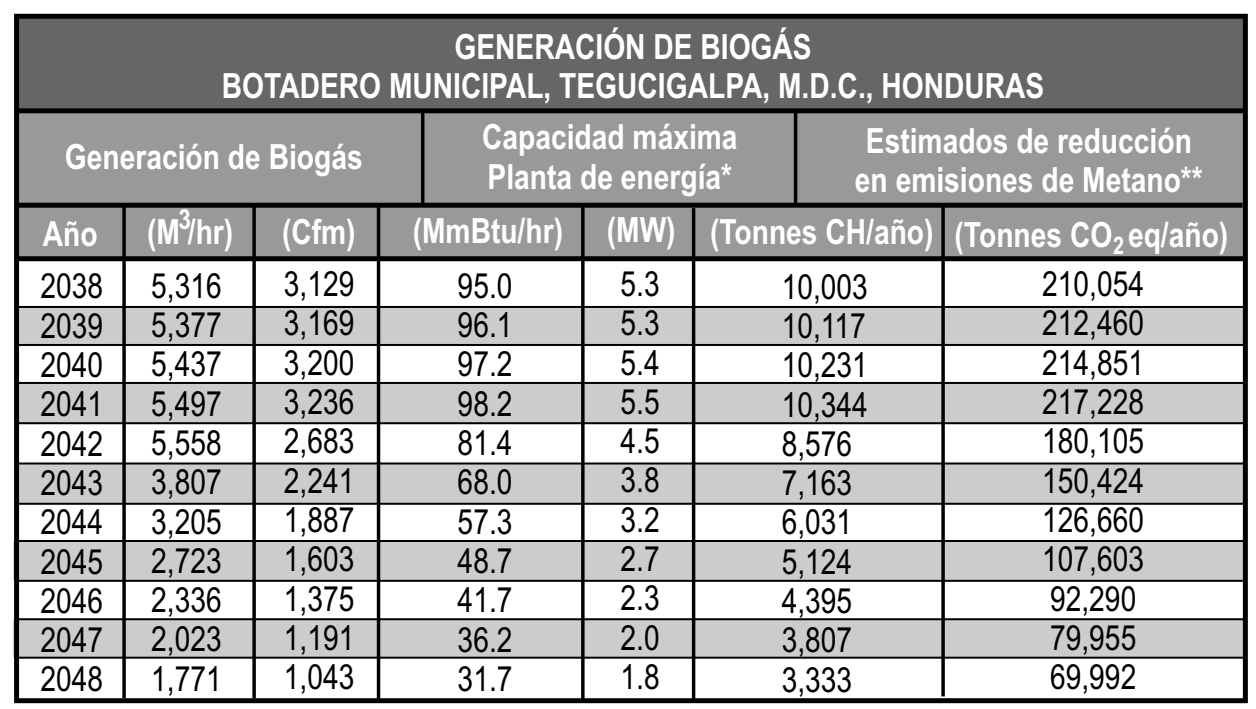

\section{CONCLUSIONES}

1. La implementación de un proyecto de generación de energía eléctrica utilizando celdas de combustible en base a metano, aplicado a la Ciudad Universitaria, resulta no factible técnicamente, debido a que la cantidad de biogás que se puede generar utilizando sólo los residuos sólidos y las aguas residuales propios de la universidad es muy poca $\left(25 \mathrm{~m}^{3} / \mathrm{h}\right)$, en comparación a los requerimientos establecidos por la planta $\left(78 \mathrm{~m}^{3} / \mathrm{h}\right)$, con lo que sólo se generarían $31.25 \mathrm{~kW}$ de los 300 kW que puede generar la planta; lo cual representaría una mala inversión y al mismo tiempo no se cumpliría con la demanda energética que se pretende suplir.

2. Aplicando el Modelo Centroamericano del Biogás se concluye que resultaría factible implementar un proyecto de generación de energía eléctrica utilizando biogás como combustible, aplicado al botadero municipal de Tegucigalpa, esto debido a la considerable cantidad de biogás que se obtendría utilizando un relleno sanitario $\left(5,497 \mathrm{~m}^{3} / \mathrm{h}\right)$, con el cual, se podrían generar hasta $5.5 \mathrm{MW}$ de potencia que representarían una importante ayuda a la actual demanda energética que atraviesa laENEE. 


\section{BIBLIOGRAFÍA}

Alternativa de utilización de biogás en rellenos sanitarios en Colombia Fundación Universitaria Iberoamericana, Universidad de las palmas de Gran Canaria (España)

Andino, Lennin. Cáceres, Marcio. "Celdas de Combustible" Seminario de Investigación (IE-900), I periodo 2007

Ávila, Karina. Maradiaga, Nubia. Escoto, Joel. "Alternativas de Generación, Sistemas de Potencia en base a Celdas de Combustible" Seminario de Investigación (IE-900), I periodo 2007

Celdas de Combustible"

http://es.wikipedia.org/wiki/piladecombustible

Celdas de Combustible" Http://www.geocities.com/patodonald2000/fuelcell/

Fuel Cell Energy" Http://www.fce.com/

Manual de usuario modelo centroamericano de biogás, versión 1.0 Programa Landfill Methane Outreach Agencia para la Protección del Ambiente (U.S. EPA) Washington, DC.

Manejo de los residuos sólidos en Honduras". Informe de la evaluación regional de los servicios de manejo de residuos sólidos municipales en América Latina y el Caribe (OPS, 2005).

Ortiz, Roberto. Mejía, Osman. Sabillón, Jairo. "Proyecto de Biomasa para Generación", de Energía Eléctrica Aplicado a la Ciudad Universitaria" Seminario de Investigación (IE-900), II periodo 2007

Proyecto, Escuela Agrícola Panamericana El Zamorano http://www.aquavita.com

Tipos de Celdas de Combustible. Fuel Cells 2000 http://www.worldwide.fuelcells.org

Todo lo que siempre quiso saber acerca de celdas de combustible" http://www.claudio-otero.cl/fuel_cells/ 